\title{
The Construction Technology of Wind Blown Sand Fill Subgrade
}

\author{
Xiaofang $\mathrm{Li}^{1}$ \\ Xijing University, 710123, Xi'an, China \\ E-mail: lixiaofangxijing@126.com \\ Shidan $\mathrm{He}^{2}$ \\ Xijing University, 710123, Xi'an, China \\ E-mail: 315705804@qq.com
}

\author{
Weiling Teng ${ }^{3}$ \\ Xijing University, 710123, Xi'an, China \\ E-mail: 370374964@qq.com
}

\begin{abstract}
The filling process and construction technology of wind-blown sand subgrade were explained aiming at emphasis and difficulties of railway engineering, combining with special construction condition of wind-blown sand filling subgrade. The results pointed out that wind-blown sand subgrade construction technology using sprinkling and vibration roller rolling solved the compaction problem of wind-blown sand subgrade, and ensured construction quality.
\end{abstract}

Keywords-Windblown Sand; Construction Technology; Compaction; Environment

\section{INTRODUCTION}

Wind-blown sand subgrade is generally used in the desert and Gobi region, the environment of this area is very harsh, especially there is still a liquidity [1]. During the construction of roadbed filling, the transportation vehicle was easily get into sand, and material feeding is very difficult. But using wind-blown sand as the material of filling subgrade in sand, it can management the sand damage, as well as fully solve the problem of lack of subgrade filling. And its advantages are obvious: wide material sources, low cost, less post-construction settlement. Although wind-blown sand is excellent subgrade filling materials, but also different from general subgrade filling [2]. So for wind-blown sand subgrade construction must take special construction process and compaction method to ensure the quality for wind-blown sand subgrade construction.

Use of wind-blow sand filling roadbed, not only can comprehensive governance, but also returning and stretched out the field. And in the irrigation area, paddy field, soft foundation for wind-blown sand subgrade filling, it can block the capillary water a good effect and enhances the stability of roadbed [3]. Wind-blown sand is different with conventional materials that subgrade filling, so the wind-blown sand subgrade construction must take special construction process and compaction method to ensure the quality of wind-blown sand subgrade [4]. At the same time, reasonable and effective environmental protection measures should be taken, such as closed for wind-blown sand subgrade protection, reduce the wind erosion phenomenon to avoid polluting the environment and the surrounding land. Wind-blown sand subgrade must attach great importance to the construction of wind-blown sand in strict accordance with the construction technology for wind-blown sand subgrade filling, aiming at all kinds of problems in the construction, take reasonable and effective solution, for wind-blown sand subgrade construction quality and to ensure that the project's overall progress [5].

The Key problem in construction of wind-blown sand is purling, inadequate water spraying method had a great influence on the construction quality of the accumulating sand in the wind. Sprinkling water on construction often appear uneven, incomplete and lead to the problem of wind-blown sand compaction degree, at the same time also lead to haul vehicles at the time of loading to miss phenomenon, seriously affect the construction progress. The construction of Wind-blown sand need timely watering, so it must ensure that there is plenty of water and water equipment. It is very important for wind-blown sand spraying method when sprinkling water scene, so it must be timely, quantity, uniform, and must take the way of the compartment, after the wind-blown sand flat, using artificial building block water twist, to frame the windblown sand [6]. The filling process and construction technology of wind-blown sand subgrade were explained aiming at emphasis and difficulties of railway engineering, combining with special construction condition of windblown sand filling subgrade, the results pointed out that wind-blown sand subgrade construction technology using sprinkling and vibration roller rolling solved the compaction problem of wind-blown sand subgrade, and ensured construction quality [7].

\section{FILLING CONSTRUCTION TECHNOLOGY}

\section{A. Compacting Criteria}

Wind-blown sand embankment, zero fill and embankment base compaction was no less than $94 \%$. Calculated the maximum dry density should be adopted in compaction degree and compaction process. Water drop method and bulldozers layered rolling vibration full water should be adopted in cases determined by the maximum dry compaction density value calculation, in the condition of natural water content or sprinkler bulldozers or vibratory roller layered crush dry vibration method should be adopted as determined the maximum dry density of compaction degree value calculation. 


\section{B. Comparison of Several Kinds of Compaction Method}

Wind-blown sand filling compactness with relative density is defined as [8]:

$$
D_{V}=\frac{\rho_{d}-\rho_{\min }}{\rho_{\max }-\rho_{\min }}
$$

Where $\rho_{d}$ is dry density; $\rho_{\min }$ is the minimum dry density; $\rho_{\max }$ is the maximum dry density.

\section{TABLE I. Characteristics Type}

\begin{tabular}{|c|c|c|c|c|}
\hline No & Type & $\begin{array}{c}\text { Thicnes } \\
\text { s } \\
/ \mathrm{cm}\end{array}$ & $\begin{array}{c}\text { Moistur } \\
\mathbf{e} \\
/ \%\end{array}$ & $\begin{array}{c}\text { Relative } \\
\text { Density } \\
/ \%\end{array}$ \\
\hline Road roller & $\begin{array}{l}\text { fine } \\
\text { sand }\end{array}$ & 30 & 2.5 & 67 \\
\hline Push dozer & $\begin{array}{l}\text { fine } \\
\text { sand }\end{array}$ & 30 & 1.8 & 65 \\
\hline $\begin{array}{l}\text { waterfloodin } \\
\mathrm{g}\end{array}$ & $\begin{array}{l}\text { fine } \\
\text { sand }\end{array}$ & 60 & 8.0 & 59 \\
\hline $\begin{array}{c}\text { Rolling } \\
\text { compaction }\end{array}$ & $\begin{array}{l}\text { fine } \\
\text { sand }\end{array}$ & 60 & 14.2 & 78 \\
\hline Push dozer & $\begin{array}{l}\text { fine } \\
\text { sand }\end{array}$ & 30 & 5.5 & 51 \\
\hline
\end{tabular}

It can be seen that road roller and bulldozer rolling compaction effect is good, high efficiency. Because of this period of deep buried groundwater, water is not enough, the water spraying is adopted and vibration road roller.

\section{Identify the Types of Wind-Blown Sand}

For wind-blown sand subgrade filler used, although particle uniform, there are many differences, but also for wind-blown sand subgrade must be formed for this scope, earth-fetching area to do detailed investigation, sampling, and do soil tests, and are classified according to the following regulations.

TABLE II Characteristics Type

\begin{tabular}{cccc}
\hline $\begin{array}{c}\text { Typ } \\
\mathbf{e}\end{array}$ & Soil/mm & $\begin{array}{c}\text { Qualit } \\
\mathbf{y}\end{array}$ & Mode \\
\hline I-I & $<0.074$ & $5 \%$ & Plastic \\
I-II & $<0.074$ & $10 \%$ & ductility \\
II & $<0.074$ & $15 \%$ & Plastic \\
& & & \\
III & $<0.074$ & $25 \%$ & Plastic \\
\hline
\end{tabular}

D. Filling Construction Technology

Construction process is as follows:

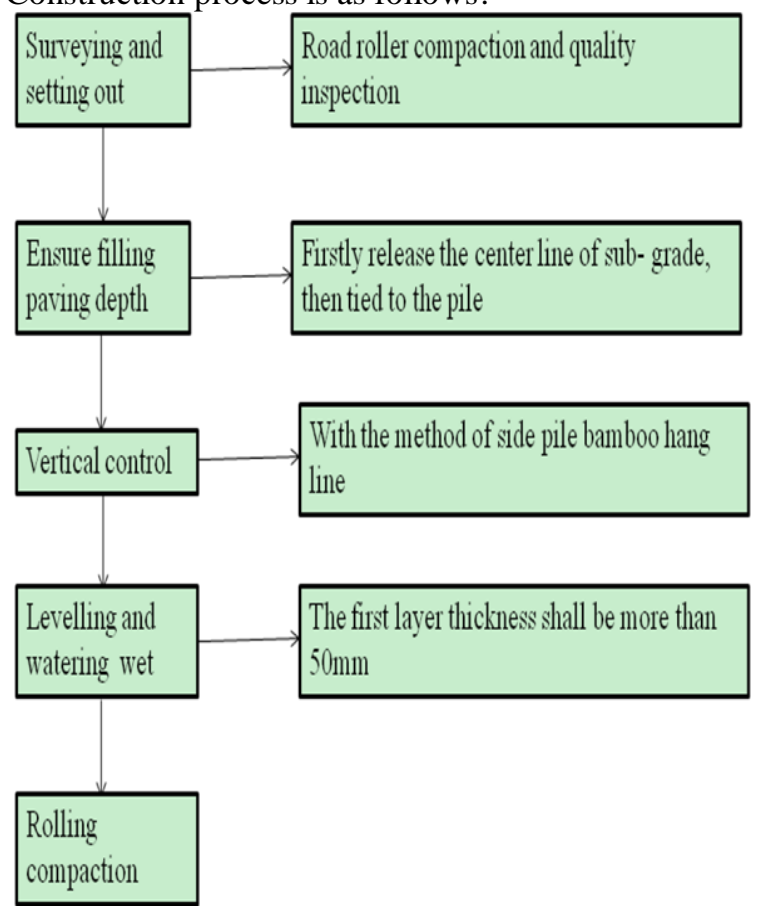

Figure 1. Construction Process

\section{THE MAIN PROBLEMS AND SOLUTIONS}

\section{A. Wind Blown Sand Purling Problem}

The Key problem in construction of wind-blown sand is purling, inadequate water spraying method had a great influence on the construction quality of the accumulating sand in the wind. Sprinkling water on construction often appear uneven, incomplete and lead to the problem of wind-blown sand compaction degree, at the same time also lead to haul vehicles at the time of loading to miss phenomenon, seriously affect the construction progress [9]. The construction of wind-blown sand needs timely watering, so it must ensure that there is plenty of water and water equipment. It is very important for wind-blown sand spraying method when sprinkling water scene, so it must be timely, quantity, uniform, and must take the way of the compartment, after the wind-blown sand flat, using artificial building block water twist, to frame the windblown sand. Then for each grid sprinkler, sprinkler uniformity to time shall prevail, other lattice sprinkling time in this shall prevail, With the method of frame for sprinkler, ensure the sprinkler uniformity, prevent spread and spread, the phenomena of leakage to ensure the construction quality of the accumulating sand in the wind.

\section{B. Environmental Pollution}

In the process of wind-blown sand transport and construction, often exist environmental pollution problem which wind-blown sand was blown up to the air. So it must take large tonnage dump truck to transport the windblown sand and the truck was in good condition and requirement. In the process of transportation, the trunk should closed well to avoid sand leakage phenomenon. 
Since the water content of wind-blown sand is low in general, so it can take water wet method or canvas covering method after loading to reduce the pollution to the environment.

When using wind-blown sand filling, except to be closed on subgrade construction, semi fixed sand dunes with low vegetation coverage outside the lines, for engineering construction disturbance of sand dunes, outside the roadbed slope foot (top), the upper hand within the scope of $30 \mathrm{~m}, 20 \mathrm{~m}$ leeward side mesh barrier of vegetation, in order to achieve the effect of windbreak and sand fixation [10].

\section{Water Seepage Problems}

When wind-blown sand subgrade filling at a certain height and higher service road, part of the water in windblown sand subgrade will gradually seepage slope and flow to the pavement under the effect of gravity and the upper pressure. Water seepage caused the collapse of slope foot and immerse service road, the road damage serious impact the traffic, so it must strictly control wind-blown sand sprinkling water and do not blindly for large amounts of water.

At the same time, drainage measures must be taken to protect embankment slope toe and sidewalks. Every certain distance on the pavement should dig a drainage ditch, blind ditch in rubble fill in $2 \sim 4 \mathrm{~cm}$. But as a result of wind-blown sand along with the water penetration into the blind ditch often causing water blockage, the effect is not obvious. Also can be directly set to dig a shallow groove, but slightly influence to the transportation.

\section{The Old Roadbed Widening Processing Problem}

This blocks the right side existing the old road widening conversions and need to solve linking problem widened section and the old roadbed, the method is to dig the steps the existing old roadbed slope, slope excavation steps before you will be on the existent drainage, protection installations dismantled and shipped to abandon soil buried, then turns the soil subgrade slope is clean (20 $\mathrm{cm}$ thick). Grading the steps from bottom to top, the first step and subgrade base processing invisible and filling and rolling together, each step height of $100 \mathrm{~cm}$, and $2 \%$ of the cross-sectional slope, layered together with the new roadbed filling and compaction.

When comes to construction steps, after waiting for the lower level filling compaction, then the upper steps excavation work, soil digging step directly fill to roadbed fill use. Lateral steps to dig the pavement base $1.2 \mathrm{~m}$ place to stop, bottom in the processing of the new and old road junction laid a layer of geo-grids, on the part of its overexcavation cushion inside edge to widen the road. Backfill soil aggregate and compaction with the new part of the road bed (as the old embankment height is less than the old pavement structure layer thickness is $120 \mathrm{~cm}$, with the original from the road on the ground following dig $120 \mathrm{~cm}$ at the top of the bed, and widen the new part base processing joint filling and rolling, and meet the requirements of the corresponding degree of compaction.

\section{E. Trapped Truck Problem}

When construction the second layer in wind-blown sand, wind-blown sand material handling truck often exist on trapped sand. Due to the wind-blown sand itself belongs to the unstable material, sand-cast phenomenon is serious after the surface water loss, so the truck sank in the wind-blown sand on the surface of the car. Before loading the material, the wind-blown sand surface must be wet by a large number of water, it can also take small push to compact the pressure on the table, or take bamboo basketry, board to build temporary driveway, prevent the truck trapped, but quite tedious. Skip on the road of windblown sand ramp must adopt the reasonable grading gravel or crushed stone slag building. For immediate reverse skip into the discharge point to prevent heavy skip over the wind-blown sand truck parking, switching and sink.

\section{F. Development Prospect}

After completion the wind-blown sand filling roadbed, the test result found out that the indicators all meet the design requirements value and stable performance. Use wind-blown sand as subgrade filling material not only need advanced technology but also need design science, simple construction, convenient detection, special equipment and testing instruments. The main important thing is that on the premise of not reduce design standards, instead of make full advantage of the local abundant windblown sand material, maximum limit reduces the project cost. According to conservative statistics, per kilometer highway at least can reduce 0.5 million Yuan. Wind-blown sand filling roadbed construction technology application provides a new road materials and new construction method, for in the construction of highway engineering on the edge of the desert and desert areas have far-reaching significance.

\section{CONCLUSIONS}

Construction of wind-blown sand looks be like simple, but actually it's quite complicated. Wind-blown sand subgrade must attach great importance to the construction of wind-blown sand in strict accordance with the construction technology for wind-blown sand subgrade filling, aiming at all kinds of problems in the construction, take reasonable and effective solution, for wind-blown sand subgrade construction quality and to ensure that the project's overall progress.

\section{ACKNOWLEDGMENT}

This work is supported by the Natural Science Foundation of Xijing University (No. XJ140217).

\section{REFERENCES}

[1] Ji Qingfeng. Wind-blown sand block technology research. Inner Mongolia science and technology and economy,2010,pp.90-92

[2] Zhang Aixia, Wang Junlin. Subgrade moisture content on the quality of the subgrade engineering Inner Mongolia highway and transportation. 2004

[3] Zhang Kejia. Wind-blown sand properties and its application in road engineering. Western exploration engineering.2012

[4] Wang Xuefei, Han Junping. The key point of control and the construction method of windblown sand. Shanxi building. 2004

[5] Wang Hailiang, Ou Xiangping. Wind-blown sand block technology research and its application in highway engineering. Transportation and technology. 2010

[6] Jueping Bu, Yongfeng Cui, Hideki Harasawa. Research on Grey Sliding Mode Control of Motor System of Fruit Harvesting 
Manipulator Joint. Advance Journal of Food Science and Technology, Vol.7, No.8, 2015, pp.566-572.

[7] Shuanghe $\mathrm{Yu}$, Wenyi Qiang and Peichen Fu. Chattering-free Discrete Quasi-sliding Mode Controller. Control and Decision, Vol.16, No.3, 2001, pp.380 -382.

[8] Weibing Gao. Variable structure control theory and design procedures. Beijing: Science press.1996
[9] Xiuying Tang and Tiezhong Zhang. Robotics for Fruit and Vegetable Harvesting: a Review. Robot, Vol.7, No.1, 2005. pp.9096.

[10] Jameslu glowei. Facing the sustainable development of urban traffic system comprehensive evaluation method research. Journal of civil engineering, Vol.5, No.3, 2004, pp.99-104. 